\title{
Mulheres pescam, sim: pesca artesanal continental em Porto Said, Botucatu [SP]
}

DOSSIER ÁGUA E MULHER

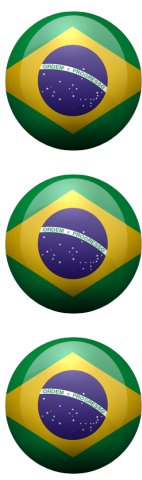

\section{Berenice Pereira Balsalobre}

Diretora e curadora do Museu de Mineralogia Aitiara (MuMA), Mestranda no Programa de Pós-Graduação em Ensino e História de Ciências da Terra, Instituto de Geociências, Universidade Estadual de Campinas. Advogada (USP) e geógrafa (UnB). Botucatu [SP] Brasil <bere.balsalobre@gmail.com>.

\section{Mariana Baggio Annibelli}

Mestre em Direito Econômico e Social (PUC-PR). Conselheira do Conselho de Meio Ambiente de Cachoeira da Mata. Advogada (PUC-PR) e geógrafa (UFPR). Botucatu [SP] Brasil <mariana.annibelli@gmail.com>.

\section{Isadora Balsalobre Athias}

Historiadora (Unesp), graduanda em Arqueologia e Preservação Patrimonial (Univasf), e Coordenadora do Educativo do Museu de Mineralogia Aitiara (MuMA). Botucatu [SP] Brasil <isadora_athias@hotmail.com>.

\section{Resumo}

Apesar da negação histórica e do descaso do poder público, as mulheres pescadoras de Porto Said, às margens da represa da Usina Hidrelétrica -UHE Barra Bonita, no Rio Tietê, SP, existem sim. Elas praticam pesca profissional artesanal e mantém uma relação de identificação e afeto pelo Rio Tietê. Vivem em moradias precárias, montadas há quase vinte anos, dentro da Área de Preservação Permanente (APP), sem saneamento básico, distante da cidade, convivendo com a precariedade do transporte público, da água potável e da energia elétrica, situação que se prolonga hodiernamente. As pescadoras conseguem seu sustento da pesca, e sentem na pele as dificuldades oriundas do esquecimento do poder público local. É imprescindível que morem às margens da represa, para que possam continuar exercendo a profissão de pescadoras. Na base do processo de descaso do poder público com a Vila dos Pescadores de Porto Said está a falta de pesquisa e levantamentos de dados sobre as necessidades desta comunidade, de maneira a criar políticas públicas que as beneficiem. Há muitos anos houve a promessa da construção de moradias, o que não aconteceu ainda, apesar de Botucatu ser beneficiada por milhares de casas do programa Minha Casa Minha Vida. As pescadoras são elos fortes na construção desta Vila, do trabalho realizado e na resistência para continuarem a exercer esta profissão.

\section{Palavras-chave}

Usina Hidrelétrica Barra Bonita. Mulheres pescadoras. Porto Said. Identidade ambiental.

\section{Women do fish: continental artisanal fishing in Porto Said, Botucatu [state of Sao Paulo] Brazil}

\begin{abstract}
Despite the historic denial and neglect of Public Power, the Porto Said fisherwomen, on the banks of the Barra Bonita Hydroelectric Power Plant dam, on the Tietê River, SP, do exist. They practice artisanal professional fishing and maintain a relationship of identificathion and affection for the River Tiête. They live in precarious housing, set up almost twenty years ago, within the Permanent Preservation Area (APP), without basic sanitation, away from the city, living with the precariousness of public transportation, drinking water and electricity, a situation that continues until today. The fishermen get their livelihood from fishing, and they feel the difficulties arising from the forgetfulness of the local Public Power. It is imperative that they live on the banks of the dam, so that they can continue to exercise the profession of fishermen. At the base of the process of neglect of the public power with the Village of Fishermen of Porto Said is the lack of research and data surveys on the needs of this community, in order to create public policies that benefit them. For many years, the construction of housing was promised, which has not happened yet, although Botucatu is benefited by thousands of homes in the Minha Casa Minha Vida program. The fishermen are strong links in the construction of this Village, the work done and the resistance to continue to practice this profession.
\end{abstract}

\section{Keywords}

Barra Bonita Hydroelectric Plant. Fisherwoman. Porto Said. Environmental identity. 


\title{
1. Introdução
}

\author{
Por que águas frias, \\ fazem companhia no amanhecer? \\ Quando alguém há alguém \\ Que inspire do teu bem querer? \\ Desafia o homem, tem que ir a luta, \\ Pescar é conduta do grande destino. \\ $A$ vida é confusa, \\ Sonhos... improvisos \\ Eu fico com os sonhos \\ Mas, pescar é preciso.
}

Luzanete Lima, Taiba, São Gonçalo do Amarante [CE] / (pescadora)

As frentes de trabalho onde as mulheres se engajaram mais ativamente no pós-Revolução Industrial são inúmeras e bastante diversificadas. 0 mercado de trabalho vem absorvendo o labor feminino avidamente há quase dois séculos. Hoje, no dito popular, a mulher ocupa qualquer função. Mas esta frase não reflete a realidade. Mulheres sofrem inúmeros preconceitos, alguns explícitos, outros sutis, muito embora sejam a maioria no mercado de trabalho, nas mais distintas funções.

Historicamente a participação das mulheres nas atividades pesqueiras foi sendo negada no Brasil desde o Século XIX, até os idos de 1980/1990, quando atividades produtivas de pequeno porte e realizadas no âmbito familiar passaram a ganhar ênfase, emergindo, assim, a nomeação da "mulher pescadora" (Fonseca, 2014, p.13-14).

Apesar da negação histórica, as mulheres pescadoras sempre estiveram participando das atividades pesqueiras, quer seja embarcadas, em coletas na beira d'água ou em terra, nas atividades de evisceração e beneficiamento de pescados, quer seja comercializando ou tecendo redes artesanais de pesca.

A construção da Usina UHE Barra Bonita, no rio Tietê, formou um represamento que inundou parte da área de 13 municípios, entre eles Botucatu, propiciando alguns locais de desembarque para o acesso ao rio, como o caso em tela, o Porto Said. Às margens da barragem, de forma espontânea e desordenada, foram-se agregando famílias de pescadores, em sua maioria, nordestinos, que ao longo de 20 anos formaram a Vila de Pescadores de Porto Said. Com morada no local de trabalho, quer dizer, barracos próximos às margens da represa, facilitando o embarque e desembarque para a prática da pesca profissional artesanal. Essa atividade proporciona o principal sustento das famílias, formadas por 112 moradores, de acordo com dados do Censo Demográfico de 2010 (IBGE, 2010), sendo 57 mulheres e 55 homens, em idades variadas, que tem na pesca artesanal o seu principal sustento.

No município de Botucatu, além da negação histórica com relação às pescadoras e pescadores, existe um estigma que há anos acomete as pessoas que vivem às margens desse represamento, no sentido de entendê-los como "ladrões" e "vagabundos". 0 estigma caracteriza as pessoas como diferentes, fora de um determinado contexto social. "O estigma social surge nas relações de afirmação de identidade entre os indivíduos de uma sociedade e funciona como um dispositivo de exclusão. Para as pessoas da sociedade, pescador não presta. Para elas, pescador deveria ficar fora da sociedade" (Efe, 2009, p. 69).

Por outro lado, a ocupação das margens do rio Tietê construiu uma nova resignificação para o local, como o lugar do trabalho, da morada, da proximidade com a natureza e o desenvolvimento do afeto dentro desta ocupação do espaço habitado, formando um ciclo complexo de relações que se desencadeiam ao longo dos anos de ocupação.

Segundo Efe (2009, p. 37) citando Freitas e Annunciato (2008, p. 114) apud São Paulo (1957), [...]

[...] particularmente, o aparecimento e a evolução das ocupações às margens do Rio Tietê impõe desvelar as relações interculturais que se desencadearam ao longo do tempo, permitindo, ainda, refletir sobre a evolução do uso de suas águas e as culturas ribeirinhas constituídas, o complexo, múltiplo e dinâmico processo de ressignificação do Rio Tietê. 
Nesta relação complexa de ocupação do espaço, a Vila de Pescadores de Porto Said e a construção social desta comunidade se desenvolve como uma identidade de resistência, que é um componente importante na formação da identificação de muitos povoamentos. Os moradores, em sua grande maioria são oriundos do nordeste, migrando para garantir a sobrevivência, seguindo percurso das águas. "Moramos onde tem água e dá para pescar", nos diz uma pescadora.

O Poder Público está presente nesta Vila de Pescadores de forma esporádica e paliativa, sem efetivar ações que possam melhorar as condições daquele precário contingente de pessoas.

\section{Porto Said}

A comunidade de pescadoras e pescadores de Porto Said, Botucatu [SP] está localizada às margens do Rio Tietê, junto ao Reservatório da UHE Barra Bonita, que desde a sua formação, tem se transformado em uma questão socioambiental complexa. De acordo com Nardi Efe (2009, p.18), desde [...]

[...] a construção da usina na década de 1960, (pela Companhia Energética de São PauloCESP, atualmente a sucessora da CESP é a concessionária AES Tietê), já se iniciaram os problemas sociais e ambientais. Sociais no que diz respeito à "retirada" das populações das margens do rio para a construção da represa; ambientai, pois, na medida em que se muda uma dinâmica natural de um rio, muda-se todo o ecossistema em volta, como, por exemplo, a fauna nele existente. Onde antes se tinha fauna piscícola nativa, com variadas espécies de peixes, agora, com a mudança da dinâmica do rio que se tornou em água represada, a fauna nativa não sobrevive mais devido à escassez de oxigênio. $O$ que se vê atualmente $e$ que tem sobrevivido são espécies de peixes exóticas que foram introduzidas. Por exemplo, na área de estudo, foi a introdução da tilápia do Nilo, que é uma das espécies que tem sobrevivido e se transformou em fonte de renda para muitas famílias que vivem nas margens da represa. [...] Só que, sendo estas margens área de preservação permanente (APP), a presença dessas pessoas configura-se, assim, um problema socioambiental.

O reservatório de UHE Barra Bonita foi o primeiro grande aproveitamento hidrelétrico da CESP (Companhia Energética de São Paulo) - formado em 1962 com o barramento do Rio Tietê, que inundou uma área de 31.000 hectares. Abrange 13 municípios, e entre todos, Botucatu foi onde ocorreu a maior quantidade de pontos de desembarque (Figura 1), sendo eles, Ponte do Jaú, Mina Velha, Porto Said e Rio Bonito. (Castro et al., 2008, p. 10).

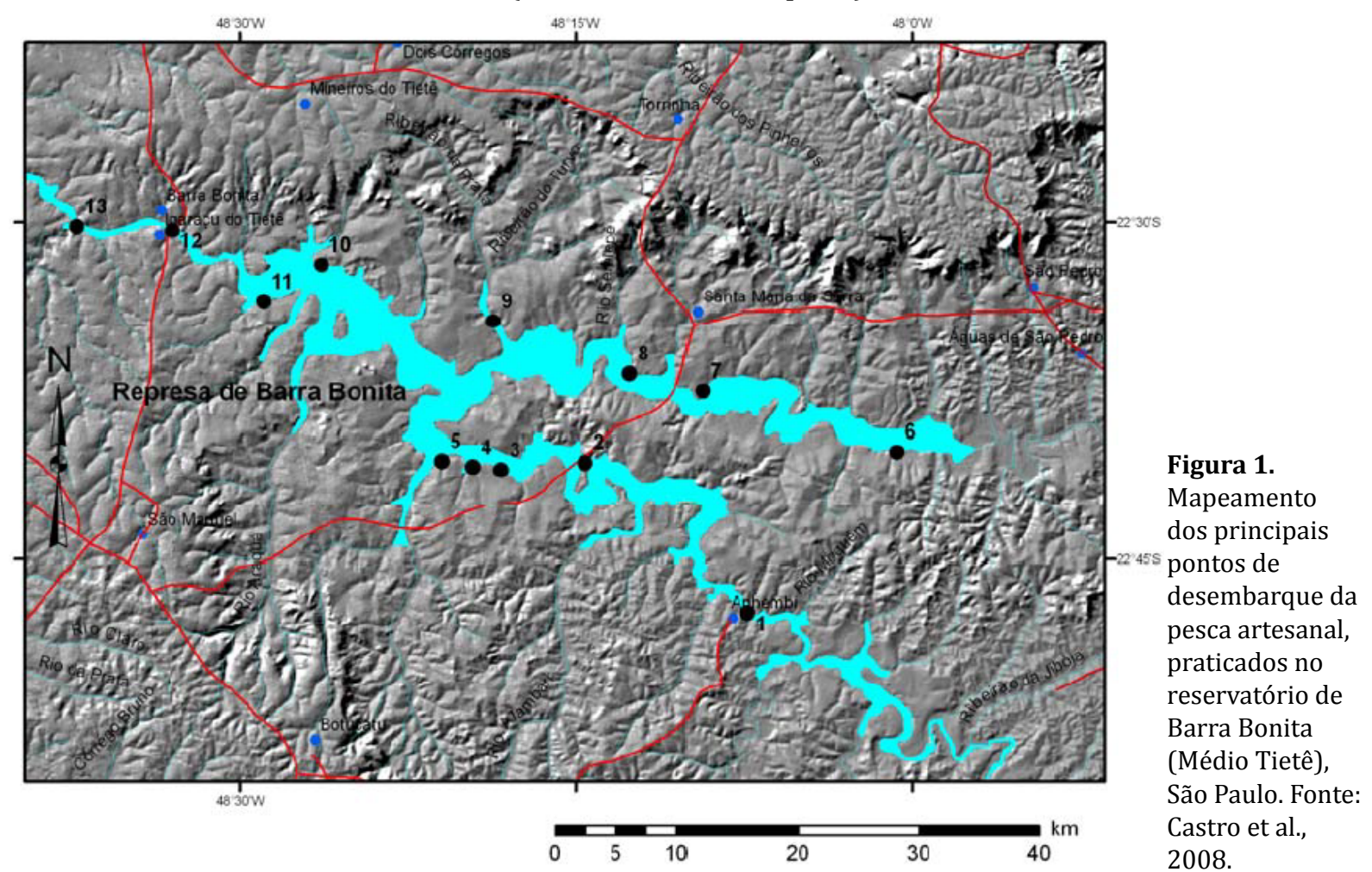

(C) Labor \& Engenho, Campinas [SP] Brasil, v.12, n.2, p.230-239, abr./jun. 2018. 
A vila de pescadoras e pescadores de Porto Said existe há aproximadamente 20 anos, na forma de sua atual configuração espacial. Anteriormente, alguns pescadores armavam barracas às margens da represa de forma temporária e esporádica. Hoje a comunidade é estruturada como um pequeno e precário vilarejo, denominado Vila de Pescadores. As famílias que ali residem têm na pesca sua principal atividade de sustento. Praticam a pesca profissional artesanal e todos estão licenciados para tal atividade, através do Cadastro Único para Programas Sociais do Governo Federal.

Esta Vila de Pescadores ocupa uma área próxima à represa, em sua maior parte inserida em Área de Preservação Permanente (APP), com pouca visibilidade social e distante $30 \mathrm{~km}$ da cidade. Não possui rede de esgoto, nem acesso à rede segura de água potável e energia elétrica (contam apenas com ligações clandestinas denominadas 'gatos'). As habitações são barracos improvisados (Figuras 2 e 3), construídos com grandes placas de lixa reutilizadas de empresas beneficiadoras de madeira, sem qualidade térmica adequada à condição de vida humana, construídas próximas umas às outras, com ruelas por onde corre o esgoto a céu aberto, que drena diretamente e in natura para a represa de Barra Bonita.

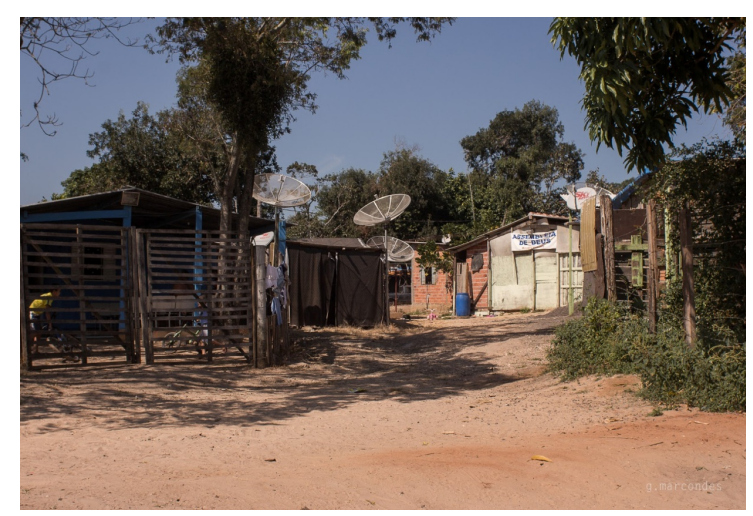

Figura 2: Conjunto de barracos da Vila de Pescadores. Foto: Marcondes, 2018

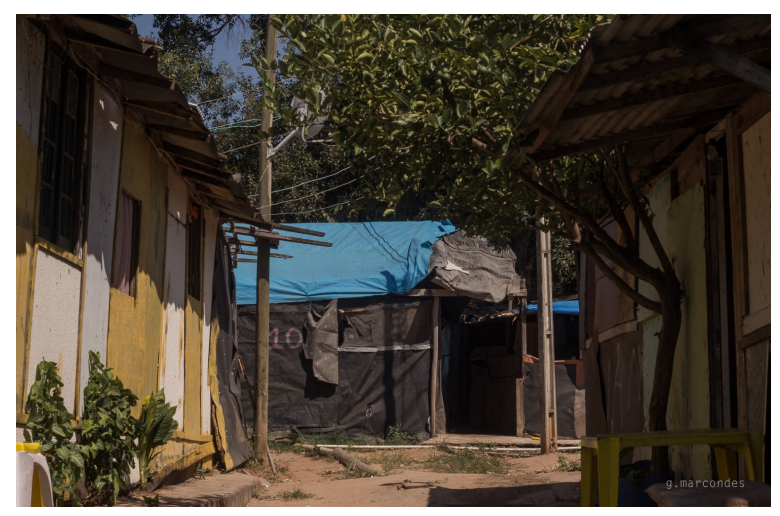

Figura 3: Barracos improvisados com lixas reutilizadas de empresas beneficiadoras de madeira. Foto: Marcondes, 2018.

De acordo com dados do Censo Demográfico de 2010 (IBGE, 2010), o Porto Said conta com 112 moradores, sendo 57 mulheres e 55 homens, em idades variadas.

Para complementar as informações acima, utilizou-se o levantamento não oficial de informações realizado para o Programa Nacional de Habitação Rural, que propunha a construção de casas para os moradores deste acampamento.

Em relação à escolaridade, $13 \%$ dos beneficiários não são alfabetizados, $21 \%$ tem o ensino fundamental completo, $56 \%$ tem o ensino fundamental incompleto, $3 \%$ tem o ensino médio incompleto, $7 \%$ tem o ensino médio completo. Considerando o estado civil, $62 \%$ são casados e ou estão em união estável, 38\% são solteiros e ou separados (IBGE, 2010).

Em relação à idade dos beneficiados: $28 \%$ são crianças, 15\% possuem entre 13 e 24 anos, 18\% pessoas entre 25 e 36 anos, $22 \%$ pessoas entre 37 e 48 anos, $9 \%$ pessoas entre 49 e 59 anos, e $8 \%$ pessoas acima de 60 anos (IBGE, 2010).

Como há dificuldades de obtenção de dados oficiais, pois esta Vila de Pescadores sofre de certa "invisibilidade" frente ao poder público, não sendo considerada, portanto, uma área de atuação prioritária. Para suprir a lacuna de dados oficiais, pesquisas de campo foram realizadas, com o intuito de conhecer melhor a realidade de vida das pescadoras e, também, suas maiores dificuldades.

Para a pesquisa deste artigo foi realizada uma conversa com a Assistente Social do Centro de Referência de Assistência Social (CRAS), de Vitoriana, distrito distante 15 quilômetros da cidade de Botucatu, unidade pública mais próxima desta Vila de Pescadores. E a partir desta conversa, ocorreram mais quatro visitas in locu, para observação, conversas e coleta de informações.

A primeira visita foi realizada juntamente com a Assistente Social do Distrito de Vitoriana, Lidiane Aparecida Reis Pinheiro e com a pescadora e moradora do Porto Said, Fernanda Keli Oliveira, além 
da representante da Secretaria Municipal do Verde de Botucatu, Fernanda Bernardi. O objetivo era conhecer este local e traçar uma linha de contato.

Na segunda visita fomos recebidas na casa da pescadora Terezinha Oliveira Araújo, paraibana, 57 anos, ajudava o pai pescador desde os 10 anos, habitante do local há 15 anos, junto com sua família.

Na terceira visita foi realizada uma pesquisa fotográfica, junto com o fotógrafo Gabriel Marcondes, documentando a desembarque da pescadora Terezinha (Fig. 4), de seu marido Francisco e do filho Tiago. Neste dia, o desembarque aconteceu em torno de 11 horas da manhã, depois de dois dias embarcados, com parada apenas para dormir, às margens do rio Piracicaba, distante uma hora de navegação do Porto Said.

Na quarta visita foi proposta uma roda de conversa onde 12 pescadoras (Tabela 1) nos receberam para uma conversa informal, embaixo de uma árvore, na beira da represa. Foi proposta uma dinâmica de conversa aberta entre todas as participantes (pesquisadoras e pescadoras), cujo relato contava com: apresentação, tempo em que vive no lugar, experiência na pesca, locais onde já pescou e outras impressões e sentimentos que tivesse vontade de expressar. Com base nessas vivências locais, percebeu-se a relação de afeto e identidade das mulheres com o rio.

Tabela 1: Relação de algumas moradoras que vivem em Porto Said.

\begin{tabular}{|r|l|l|c|c|}
\hline \multicolumn{2}{|l|}{ Nome } & Procedência & Idade & $\begin{array}{c}\text { Há quanto tempo pesca em } \\
\text { Porto Said }\end{array}$ \\
\hline $\mathbf{1}$ & Cícera Macedo Veloso & Ceará & 42 & 10 \\
\hline $\mathbf{2}$ & Luzinete J. Martins & Ceará & 48 & 17 \\
\hline $\mathbf{3}$ & Fernanda Keli Oliveira & Botucatu [SP] & 42 & 12 \\
\hline $\mathbf{4}$ & Edileusa Souza Carneiro & Ceará & 52 & 15 \\
\hline $\mathbf{5}$ & Cristiane da Silva Carias & Minas Gerais & 40 & 14 \\
\hline $\mathbf{6}$ & Marcia E. Martins & São Paulo [estado] & 19 & 10 \\
\hline $\mathbf{7}$ & Ana Lucia de Melo e Silva & Pernambuco & 42 & 15 \\
\hline $\mathbf{8}$ & Terezinha Oliveira Araújo & Paraíba & 48 & 15 \\
\hline $\mathbf{9}$ & Cícera Santos Torrice & Ceará & 45 & 17 \\
\hline $\mathbf{1 0}$ & Antonia Lucia Martins de Lucena & Ceará & 49 & 18 \\
\hline $\mathbf{1 1}$ & Patricia Rodriguez Batista & Bahia & 32 & 18 \\
\hline $\mathbf{1 2}$ & Maria do Socorro Augusto Martins & Ceará & 72 & 6 \\
\hline
\end{tabular}

\subsection{A pesca artesanal profissional e a identificação das mulheres com a represa de Barra Bonita, no Rio Tietê}

A pesca profissional artesanal é aquela onde o pescador a pratica profissionalmente e que se torna seu principal meio de subsistência, ocupando até $80 \%$ de seu tempo, exercendo-a de forma artesanal ou empresarial.

A pesca artesanal em rios e represas no Estado de São Paulo é aquela praticada por formações socioeconômicas de pequena escala ou como pequena produção mercantil, onde a pesca é a principal atividade exercida, entendida como uma profissão e cuja principal motivação é a comercialização do pescado, sendo uma parte usada para seu próprio consumo alimentar (Castro et al., 2008, p. 1).

De acordo com Instituto de Pesca do Estado de São Paulo, estima-se que existe cerca de 1.500 pescadores artesanais no Rio Tietê, em suas porções médias e baixa, localizados ao longo das seis represas existentes no curso do Rio: Barra Bonita, Bariri, Ibitinga, Promissão, Nova Avanhandava e 
Três Irmãos, no Estado de São Paulo. "No entanto, nas Colônias de Pesca não se dispõe de um cadastro real de profissionais efetivamente ligados à atividade" (Castro et al, 2008, p. 2.). Esse desconhecimento faz com que políticas públicas não sejam efetivas, pois desconhecem seus destinatários.

É possível afirmar que a visibilidade desta comunidade é relativa. 0 poder público local desenvolve uma política de 'tolerância', que se revela nos "gatos" para o acesso à água potável e energia elétrica. As pessoas que ali residem convivem com o descaso oficial e a precariedade das condições físicas do local. Mas as pescadoras do Rio Tietê existem sim. Em Porto Said são muitas, trabalhando lado a lado com os pescadores, algumas dividindo embarcações, outras em barcos exclusivos de mulheres pescadoras.

As famílias trabalham juntas, em pequenos núcleos com uma divisão de funções, de acordo com as exigências que a atividade pesqueira requer. As principais são pescar embarcado, limpar e filetar e embalar os peixes, fazer e remendar as redes, e, principalmente, o mais difícil para elas, vender a mercadoria. As unidades de pesca em sua maioria são formadas por pessoas da mesma família, que já trazem a experiência de outros locais e, muitas vezes, como função que seus avós e pais já desenvolviam.

Verificou-se que quase a totalidade dos habitantes provenientes da região nordeste do país. Adquiriram a experiência da pesca nos açudes do nordeste, depois ao longo do rio São Francisco, alguns na represa do Paranoá, em Brasília [DF], quando ainda era permitido, e atualmente às margens do rio Tietê, na UHE de Barra Bonita. Migram em busca de locais onde existe peixe. "A gente anda atrás do peixe", diz uma das pescadoras. Na represa de Barra Bonita há ainda bastante peixe, pois a concessionária da UHE Barra Bonita, AES Tietê, tem obrigação de colocar alevinos para repovoar a represa, como forma do acordo de compensação ambiental. Em que pese o relato dos pescadores alegarem que atualmente existe muita gente pescando, vivendo da pesca, e que essa grande pressão pesqueira pode dificultar a vida deles num futuro próximo.

Algumas pescam na represa da barragem, outras vão com seus barcos em direção ao Rio Piracicaba, onde atualmente há mais variedade de peixes e maior quantidade.

As pescadoras acumulam ao seu labor diário na pesca, as atividades domésticas de seus lares. Com suas duplas jornadas, cuidam da casa, dos filhos e das embarcações. Mesmo assim, ainda encontram tempo para o seu cuidado pessoal. Destaca-se aqui a vaidade das mulheres pescadoras, reforçada pela felicidade e sentimento de liberdade com que encaram a sua jornada. "Toda manhã quando eu acordo, a primeira coisa que eu faço no dia é ir olhar o Rio, que me dá uma alegria danada", afirma dona Terezinha de Oliveira Araújo, 57 anos, pescadora há 37 anos, moradora de Porto Said há 14 anos, retirante nordestina, vinda de Paraíba. Dona Terezinha pesca junto com seu filho Tiago e seu marido Francisco.

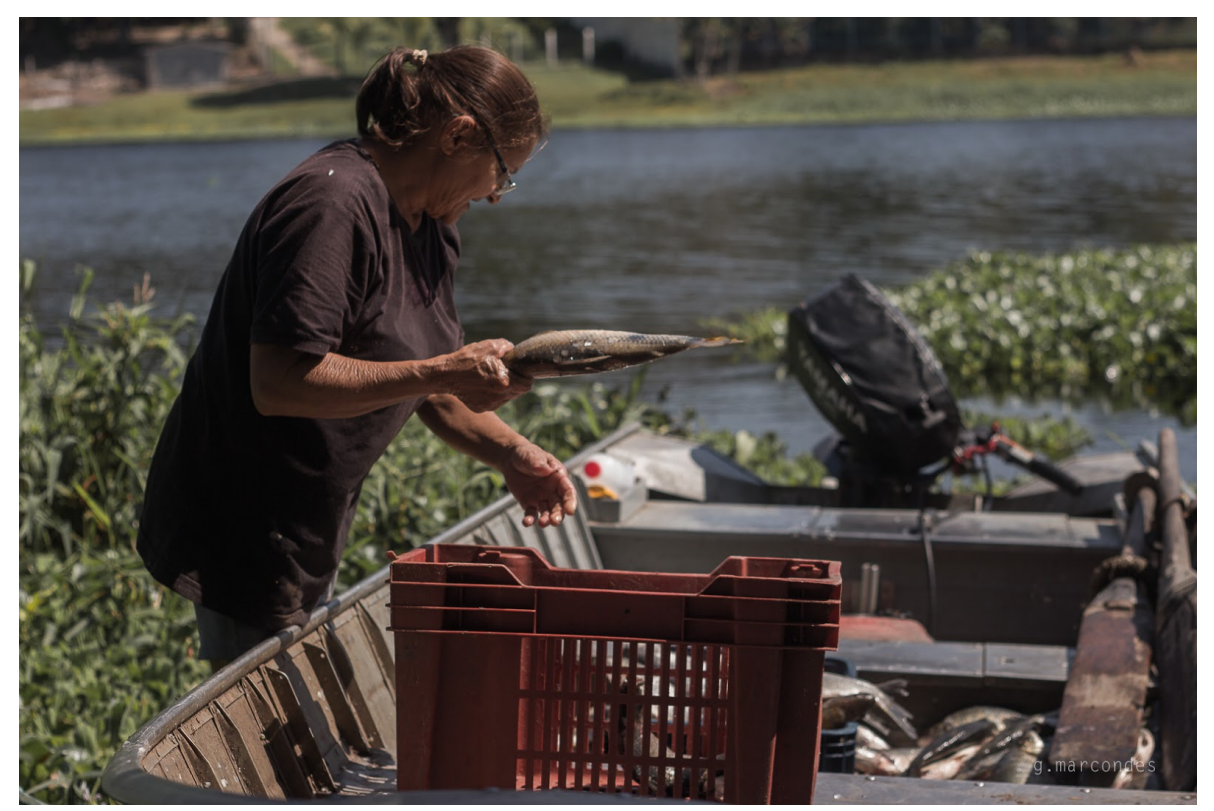

Figura 4: Terezinha Oliveira Araújo, que pesca desde os dez anos, retornando de dois dias de pesca no rio Piracicaba, separando os peixes para a próxima etapa, limpeza e filetamento.

Foto: Marcondes, 2018. 
Outras pescam na represa da barragem, outras vão com seus barcos em direção ao Rio Piracicaba, onde atualmente há mais variedade de peixes e maior quantidade. Outras gostam de jogar a rede à noite, para recolher bem cedinho, como a pescadora Fernanda Keli Oliveira.

Fernanda Kelli de Oliveira, pescadora há 12 anos, única botucatuense do acampamento, destaca, em suas falas, a alegria e felicidade em pertencer a essa comunidade, que apesar das precariedades e dificuldades, é muito unida. "Todas as mulheres olham pelos filhos de todas. Graças a Deus nunca perdemos nenhuma criança afogada no Rio". Prossegue afirmando "que não troca essa vida por nada, pois não há sentimento melhor do que o de pegar o seu barco pela manhã, e sair pelo rio, com o vento batendo em seu rosto e o único barulho que se escuta, além do barco, é o canto dos passarinhos". Fernanda pesca junto com seu atual marido.

Outras mulheres preferem pescar apenas com mulheres, em seu barco, pois afirmam que mulher entende melhor a outra mulher, afirma uma das pescadoras.

Resta evidente, na fala das mulheres pescadoras uma relação topofílica com meio. Topofilia é um neologismo definido por Tuan como "todos os laços afetivos dos seres humanos com o meio ambiente material" (Tuan, 1980, p. 107). A topofilia pode assumir assim muitas formas, variando em amplitude emocional e intensidade. Podem ser considerados exemplos topofílicos distintos a apreciação estética do meio através do turismo, o contato físico com o meio ambiente do pequeno agricultor, o patriotismo e a relação emocional da pessoa com seu lar e seus pertences. 0 termo topofilia associa sentimentos com meio ambiente e, ao fazer isso, promove a ideia de lugar. Contudo, "o meio ambiente pode não ser a causa direta da topofilia, mas fornece o estímulo sensorial que, ao agir como imagem percebida, dá forma às nossas alegrias e ideais" (Tuan, 1980, p. 129).

Apesar da identidade e afeto ao Rio, da ligação topofílica com o local onde vivem, existem inúmeros problemas, que elas enfrentam no seu dia-a-dia.

\subsection{Problemática socioambiental}

A problemática socioambiental revela-se na dicotomia entre ocupar, viver e zelar do rio. Ocupam a beira da represa de forma ilegal. Vivem da pesca. Zelam do rio, pois ali estão, olhando, navegando e coletando cotidianamente garrafas pet boiando nas águas, oriundas da grande São Paulo. Recebem muito lixo que desce pelo rio, sem origem local.

A problemática socioambiental também se manifesta na precariedade das condições de vida das pessoas, que habitam moradias improvisados, feitas com grandes lixas oriundas das indústrias madeireiras, ocupando áreas destinadas à preservação permanente, destinando seus esgotos in natura direto para a água, onde moram os seus peixes.

Essas habitações são provisórias há quase vinte anos, pois é proibida a ocupação de APP. Tanto o Código Florestal de 1965, quanto a Lei 12651/2012 (Brasil, 2012) que o revogou, no seu art. 4oㅡ, inciso III, proíbem a ocupação do entorno dos reservatórios, uma vez que a faixa de trinta metros a partir da margem oficial deve ser destinada às matas ciliares, com o intuito de proteger a qualidade das águas desses locais.

Em virtude dessa proibição, pescadoras e pescadores aguardam solução do poder público municipal em realocá-los para local adequado, em casas de alvenaria com instalações elétricas e hidráulicas e esgotamento sanitário adequados, arruamentos, recuos, arborização, calçamento e espaços de convívio social.

Escutam promessas de dois em dois anos (período eleitoral) de que suas casas finalmente sairão do papel, embora até hoje não tenham se tornado realidade. Diz Terezinha "nós somos esquecidas, mas de dois em dois anos vem gente aqui nos enganar, dizendo que sairão as casinhas e o esgoto. Isso dói. Que ninguém venha mais nos enganar!"

Alguns pescadores ainda acreditam na promessa de suas casas, outros já cansaram de esperar e começaram a construir casas de alvenaria, fora da área de APP. Há ainda algumas pessoas, que 
manifestaram-se que "no fundo do coração não queriam essas casas, queriam mesmo ficar ali onde estão, mas com autorização para estarem lá. Para eles mesmos poderem construir suas casas como gostariam, onde gostariam de estar", conforme assegura a pescadora Cristiane da Silva Carnais, de 40 anos, moradora de Porto Said há 14 anos. Em seu sentimento mais íntimo, muitas pescadoras temem que suas atividades pesqueiras sejam prejudicadas em virtude da construção dessas casas muito longe do Rio. Afinal de contas, o projeto de construção de suas casas apresentado pela Prefeitura Municipal de Botucatu chegou pronto, sem consultá-los a respeito das suas necessidades e demandas para o local onde vivem.

\subsection{Precariedade e abandono, a longa espera pelas casas}

Em virtude da precariedade e abandono, as pescadoras e pescadores esperam, há muito tempo a solução definitiva para o impasse de suas casas.

Finalmente, em 30 de junho de 2016, foi assinado pelo então Prefeito Municipal de Botucatu, Sr. João Cury, convênio com a Companhia de Desenvolvimento Habitacional e Urbano do Estado de São Paulo (CDHU), para a construção de mais de 50 casas para as pescadoras e pescadores de Porto Said, por meio do Programa Melhor Bem, Viver Melhor.

Ainda em 2016, por meio de um Termo de Ajustamento de Conduta (TAC), firmado entre a Prefeitura Municipal de Botucatu e a AES Tietê, ficou estabelecido que a Prefeitura Municipal de Botucatu, em virtude do fato dos pescadores do Porto Said ocupar irregularmente terreno da AES Tietê, adquiriu terreno da empresa, orçado em dois milhões de reais e o colocou à disposição da Companhia de Desenvolvimento Habitacional e Urbano (CDHU), para a construção de casas para os pescadores. Em contrapartida, a AES comprometeu-se a financiar projeto de revitalização da orla da comunidade vizinha, denominada de Rio Bonito.

As obras de revitalização do Rio Bonito foram entregues pela Prefeitura Municipal de Botucatu em 18 de dezembro de 2016 e as cinquenta casas dos pescadores ainda não foram construídas, sequer saíram do papel, embora exista o terreno e a dotação orçamentária para tanto.

\subsection{Alternativas econômicas para o período de Defeso}

0 período de Defeso corresponde à paralisação obrigatória da pesca sobre um determinado recurso pesqueiro (Simões, 2011). É normatizado pela Instrução Normativa do IBAMA de número 25 , de $1^{\text {o }}$ de setembro de 2009 , que estabelece em seu artigo $1^{\circ}$ que o período de defeso serve para a proteção e reprodução natural dos peixes, estando à pesca proibida no período compreendido entre $1^{\circ}$ de novembro e 28 de fevereiro, na bacia hidrográfica do rio Paraná.

Nesse período as pescadoras e pescadores estão proibidos de pescar. Para sobreviverem recebem Seguro Defeso do Governo Federal. Esse seguro corresponde a um salário mínimo por pescador.

Ocorre que para os pescadores esse valor pago é considerado pouco para suas necessidades, haja vista que em média, mensalmente, de acordo com estimativas dos próprios pescadores eles consigam obter uma renda média de $\mathrm{R} \$ 1.500,00$ (um mil e quinhentos reais) por barco. Sobrevivem com o dinheiro da pesca e somando-se a ele o valor do Programa Bolsa Família que cada família recebe.

No entanto, no período de defeso, desde 2016 o Governo Federal optou por cortar o pagamento do Bolsa Família no período em que os pescadores estão recebendo o Seguro Defeso.

Para sobreviverem resta aos pescadores "pescarem" material reciclável que boia no rio e venderem, com o intuito de complementar a renda da família, pois atualmente não há alternativa econômica para o período de Defeso.

Políticas públicas de alternativa de renda para esse período deveriam ser construídas entre o Poder Público e os pescadores. A promoção de passeios de barco poderia ser uma alternativa viável, pois o período de defeso corresponde a primavera e ao verão, período onde muitos turistas podem aproveitar o calor e os dias mais longos para conhecerem e se apropriarem do Rio Tietê; mas que para isso ocorresse, infraestrutura mínima deveria ser construída, bem como divulgação 
dos passeios deveriam ser executadas pelo poder público com o intuito de colaborar com renda alternativa aos pescadores, justo no período onde não podem exercer sua atividade principal.

Como bem destaca Castro et al (2018, p.4) "Qualquer medida de ordenamento pesqueiro, para ser bem-sucedida, deve não somente levar em conta as informações sobre pesca/ictiofauna e ambiente, mas, principalmente, inserir no contexto o principal ATOR do processo: o pescador (o seu saber empírico) e a sua comunidade". Sendo assim, é imprescindível que as políticas públicas municipais levem em consideração a relação de identidade que existe entre esta comunidade e o rio, uma vez que a subsistência da mesma reverbera sobre a condição de pertencimento, a resistência local e entre o elo afetivo das pessoas e meio natural.

A pescadora Terezinha Oliveira Araújo, paraibana, 58 anos, expressa esse sentimento: "A gente é uma família, eu amo esse povo daqui"; Cícera Santos Torrice, cearense, 48 anos, completa: "Todos se ajudam". Assim, o que dá sentido à Vila não é apenas a pesca, mas sim, os encontros casuais, as afinidades, o coletivo e o saudosismo que renovam as forças para continuarem e existindo e resistindo ali. Unir pessoas, vontades, afetos, objetivos e resistência representam a força feminina. E as mulheres pescadoras simbolizam o feminino impregnado dentro da Vila de Porto Said.

\section{Considerações Finais}

De acordo com os levantamentos realizados para este trabalho, é possível afirmar que no acampamento de pescadores do Porto Said existem pescadoras sim. Elas estão lá há quase vinte anos, em que pese o descaso e esquecimento do poder público local. Levam suas vidas na precariedade, porém gostam do que fazem e identificam-se com a represa do Rio Tietê.

Os problemas de infraestrutura da comunidade poderiam ser resolvidos com o comprometimento do poder público municipal, para as melhorias da população de pescadores, especialmente, com a construção da casa própria. A problemática socioambiental também seria minimizada. Enquanto isso, medidas paliativas vêm sendo adotadas, com a tolerância dos pescadores morando às margens da represa, em área de APP, prorrogando-se a precariedade da vida das pessoas e a poluição das águas. Essa tolerância reflete o descaso do poder público pelos pescadores. Não há pesquisas e medidas efetivas, suficientes para subsidiar soluções adequadas e permanentes.

Seria necessário um cuidado maior pela Vila dos Pescadores, no sentido da proximidade de políticas públicas e do impacto econômico que a atividade pesqueira e possivelmente a turística representa para o município de Botucatu.

\section{Referências}

Brasil (2011). Código Florestal. Recuperado de:

<http://www.planalto.gov.br/ccivil_03/_ato2011-2014/2012/lei/l12651.htm>

Botucatu (2015). Relatório final da 3ํㅡㄹ Conferência Municipal de Políticas Públicas para as Mulheres.

Barbosa, L. M. (2008) Topofilia, memória e identidade na Vila de Iapi em Porto Alegre. (Dissertação de Mestrado), Programa de Pós-Graduação em Geografia, Universidade Federal do Rio Grande do Sul, Porto Alegre, RS, Brasil.

Castro, P. M. G. et al. (n.d.). A pesca artesanal profissional extrativista continental no estado de São Paulo: uma análise crítica. Texto técnico do Instituto de Pesca do Estado de São Paulo. Recuperado de: <http:// www.pesca.sp.gov.br/pesca_artesanal.pdf>

Efe, I. N. (2009). Intercultura e Sustentabilidade, um estudo de caso centrado nas interrelações com as comunidades de pescadores de Porto Said e Rio Bonito, município de Botucatu (SP). (Dissertação de Mestrado), Programa de Pós-Graduação em Geografia, Universidade Federal de Santa Catarina, Florianópolis, SC, Brasil.

(C) Labor \& Engenho, Campinas [SP] Brasil, v.12, n.2, p.230-239, abr./jun. 2018. 
Fonseca, M. N. A. C. (2014) O papel das mulheres na atividade de pesca artesanal marinha do Município de Rio das Ostras. (Dissertação de Mestrado), Universidade Aberta de Lisboa, Rio de Janeiro, RJ, Brasil.

IBGE (n.d.). Recuperado de: <https://www.ibge.gov.br/>

Massei, R. (2007). A Construção da Usina Hidrelétrica Barra Bonita e a relação homem-natureza: vozes dissonantes, interesses contraditórios (1940-1970). Recuperado de: <https://tede2.pucsp.br/bitstream/ handle/12997/1/Roberto\%20Massei.pdf>

Simões, A. C. (2011). Sobre a época de defeso. Recuperado de: <http://www.pesca.sp.gov.br/Destaque_Defeso2011.pdf> 